\title{
Insulation Impossible: Monetary Policy and Regional Fiscal Spillovers in a Federation.*
}

\author{
Russell Cooper; Hubert Kempf; and Dan Peled ${ }^{\S}$
}

September 7, 2010

\begin{abstract}
This paper studies the interactions of fiscal and monetary policies in the presence of fiscal spillovers within a monetary union. When capital markets are integrated, the fiscal policy of any member country will influence equilibrium wages and interest rates across the whole union. Thus there are fiscal spillovers within a federation. Within a general class of monetary policy rules, there does not exist one that completely insulates agents in one region from fiscal policy in another. We contrast particular rules, such as inflation and interest rate targeting, to illustrate how monetary policy becomes a channel for fiscal policy spillovers.
\end{abstract}

\section{Introduction}

This paper studies the interactions of fiscal and monetary policies in the presence of fiscal spillovers within a monetary union. We ask whether in such a federation there exists a monetary policy rule that insulates agents in one region from the effects of fiscal policy in another. Our main finding is that such insulation is impossible.

One of the gains from the integration of capital markets between countries is a more efficient allocation of capital across economies. But, at the same time, integration implies that the fiscal policy of one country will impact agents in all countries through relative prices.

\footnotetext{
${ }^{*}$ Russell Cooper is grateful to the NSF for financial support. We thank for comments and suggestions on earlier drafts seminar participants at the University of Texas, the Bank of Canada, the Federal Reserve Bank of Cleveland, the Federal Reserve Bank of Dallas, the Federal Reserve Bank of Kansas City, the Federal Reserve Bank of San Francisco, the Banque de France, European Central Bank, University of Bern, Cardiff Business School, the University of Melbourne, Bocconi, University, the University of California at Davis, the Einaudi Institute for Economics and Finance, the Universidad de San Andresas well as participants to the T2M 2009 conference, the Banco de Espana conference on "Interactions between Monetary and Fiscal Policy" (2010), and the ESWM 2010 (Shanghaï).

${ }^{\dagger}$ Department of Economics, European University Institute, Florence Italy and Department of Economics, University of Texas, Austin, TX.78712, russellcoop@gmail.com

${ }^{\ddagger}$ Banque de France and Paris School of Economics, kempf@univ-paris1.fr

$\S$ Department of Economics, University of Haifa, Haifa 31905, Israel, dpeled@econ.haifa.ac.il
} 
One way to deal with these fiscal spillovers is through the coordination of fiscal policy between the various policymakers active in the monetary union. But doing so can run against the political pressure of national constituencies.

Alternatively, working through the institutional design of the union, countries will attempt to insulate their economies from the fiscal policies of others. This can be achieved both through restrictions on fiscal policy of member countries and through commitment to various monetary policy rules.

The goal of this paper is to study the second of these two components of insulation: the effects of monetary policy on fiscal spillovers. One direct connection between monetary policy and fiscal conditions arises in a debt crisis when a central bank finances a bail-out (see Cooper, Kempf, and Peled (2010)).

Even if a monetary authority can commit not to directly respond to fiscal measures of a member country, there are more subtle channels of interaction across countries within a federation operating through a monetary authority. Generally, the fiscal (debt) policies of large regions may impact equilibrium prices, which we term "fiscal spillover". Depending on the monetary rule in place, debt policy may elicit a response by the monetary authority. If, for example, the central bank responds to variations in prices, then fiscal spillovers create a dependence of monetary policy on regional fiscal policy. This response might not be termed a "bailout" since any reaction of the monetary authority appears to be part of the normal operating procedure of the central bank. Thus our analysis highlights the inescapable interplay between fiscal policy and monetary rules. The choice of monetary policy rules will impact on the conduct and consequences of fiscal policy by governments within a federation.

We explore these issues in a multi-region overlapping generations model with money, capital and bonds. In this model, a monetary policy rule specifies region specific transfers as a function of economy aggregates. We study the effects of the debt issued by one region on the steady state of this economy, focusing on spillovers from one region to another.

This paper is motivated by the institutional structure of the European Monetary Union. This is a leading example of a federation in which member states conduct independent fiscal policies yet there is a single central bank. Further, within the EMU there is no central fiscal authority. Thus the responsibility for any insulation falls to the ECB. In this context, our paper focuses on how the rules of the ECB interact with fiscal spillovers and why it cannot guarantee fiscal insulation.

In our analysis, we provide sufficient conditions on monetary policy for crowding out: an increase in the debt of one region reduces the capital stock of the federation. We further argue that there does not exist a monetary policy rule which would eliminate these fiscal spillovers. In particular, there is no monetary policy rule which makes the equilibrium allocation of region 2 agents independent of region 1 fiscal policy. That is, region 2 agents cannot be insulated from the level of region 1 debt. Moreover, no monetary policy rule can prevent equilibrium consumptions of agents in the two regions and the capital stock from varying with region 1 fiscal policy. From these two findings we conclude that steady state allocations cannot be insulated from the fiscal policy of region 1 .

To complement this general finding, we also provide a comparison of two commonly studied rules, one which fixes money growth and those which peg an interest rate. ${ }^{1}$ Intuitively, one might conjecture that

\footnotetext{
${ }^{1}$ Carlstrom and Fuerst (1995) also compare interest rate and money growth rules in the presence of cash-in-advance and
} 
apparently weak monetary rules such as pegging the interest rate would facilitate the redistribution of tax burdens. If a region runs a deficit, selling its debt will impact interest rates. A monetary authority striving to peg interest rates may be induced to monetize the regional debt. In doing so, it would tax the money holdings of other agents. In contrast, a strong monetary authority would fix the growth rate of the money supply and thus be immune to fiscal pressures.

We find that this intuition is misleading in a multi-region economy. First, even when the money growth rate is fixed, fiscal policy of one region can influence real money demand and thus the real value of monetary transfers. Second, by pegging an interest rate, the monetary authority can actually protect agents from the inflation tax. This occurs when the monetary authority is pegging the same interest rate that agents' obtain on their portfolios.

We also use our framework to highlight the interaction between the effects of monetary policy and market structure. If, for example, some agents do not save through intermediaries, then these agents will bear any inflation tax induced by fiscal actions of a regional government. If all capital flows are eliminated across regions, then there will exist a monetary policy to insulate agents of one region from the fiscal actions of other regional governments. In this case, insulation is possible but it requires the complete disintegration of capital market links.

\section{Multi-Region Model}

We study a multi-region (multi-country) infinite overlapping generations model with three stores of value: capital, money and bonds. ${ }^{2}$ Agents live for two periods in one of two regions, $i=1,2$. The size of each generation is normalized to 1 with a fraction $\eta^{i}$ of the agents living in region $i=1,2$.

As our focus is on the interaction between the regions and the choice of monetary rules, we study the unique monetary steady state of the overlapping generations model. Thus the presentation of the basic model ignores time subscripts.

\subsection{Households}

Households are endowed with one unit of time in youth which is inelastically supplied to the labor market in return for a real wage $\omega$. Consumption occurs in both youth and old age. Hence, households consume a portion of their wage and save the rest via an intermediary which pays a real rate of return $R$.

The household in region $i$ receives a transfer $g^{i}$ from its regional government in the first period and pays a tax of $\tau_{t}^{i}$ in period $t=y, o$ for $i=1,2$ where $t=y$ denotes youth and $t=o$ denotes old age. The household in region $i$ chooses how much to save, denoted $s^{i}$, to solve

$$
\max _{s} u\left(c_{y}^{i}\right)+v\left(c_{o}^{i}\right)
$$

portfolio restrictions in a single region monetary economy. In this paper, these two extreme policies are meant to illustrate the potential for interaction across the two regions.

${ }^{2}$ The structure is similar to that in Kehoe (1987) except that we consider a monetary economy and allow regional governments to run deficits. 
where $c_{y}^{i}=\omega+g^{i}-\tau_{y}^{i}-s$ and $c_{o}^{i}=s R-\tau_{o}^{i}$. The first-order condition for the household is

$$
u^{\prime}\left(c_{y}^{i}\right)=R v^{\prime}\left(c_{o}^{i}\right) .
$$

Here $R$ is interpreted as the rate of return offered by competitive financial intermediaries, described below. These intermediaries are open to all agents regardless of region (country). Thus financial markets are fully integrated.

Let $s\left(\omega, R, \tau_{y}, \tau_{o}\right)$ denote the savings function of a household. ${ }^{3}$ We assume $s_{R}\left(\omega, R, \tau_{y}, \tau_{o}\right)>0$ so that the substitution effect dominates and, as usual, $s_{\omega}\left(\omega, R, \tau_{y}, \tau_{o}\right)>0$.

\section{$2.2 \quad$ Firms}

Firms in both regions have access to the same constant returns to scale technology which converts labor (L) and capital (K) into the single consumption good: $Y=F(K, L)$. Firms maximize profits of $F(K, L)-\omega L-r K$ leading to $\omega=F_{L}(K, L)$ and $r=F_{K}(K, L)$. If $k \equiv \frac{K}{L}$ is the per worker capital stock, then these first order conditions become $\omega=f(k)-k f^{\prime}(k)$ and $r=f^{\prime}(k)$ where $f(k)=F(k, 1)$. Capital fully depreciates in the production process.

\subsection{Regional Governments}

The government in region 1 , denoted $R G^{1}$, is the sole active government. ${ }^{4}$ It transfers an exogenous amount $g^{1}$ to young agents of each generation and levies taxes on young and old agents. It issues a quantity $B^{1}$, per region 1 agent, of one-period debt in each period. In addition, it receives a real transfer from the central bank of $T^{1}$, per region 1 agent.

For this analysis, the fiscal policy of $R G^{1}$ is characterized by the amount of debt it issues, $B^{1}$. The difference between government transfers and taxes collected from young agents is financed by issuing debt. The taxes collected from old agents plus the real value of transfers from the central bank, $T^{1}$, are used to retire the debt in the next period. ${ }^{5}$ These flows are summarized by

$$
B^{1}=g^{1}-\tau_{y}^{1}, \quad B^{1} r=\tau_{o}^{1}+T^{1} .
$$

Here the region 1 government must pay the same return on its debt, $r$, paid to lenders by firms.

Region 2 does not make transfers to young agents, $g^{2}=0$. However, depending on the nature of operations of the central bank, the region 2 government receives transfers, $T^{2}$, which are then rebated to old agents, $\tau_{o}^{2}=-T^{2}$.

\section{$2.4 \quad$ Intermediaries}

There are intermediaries who provide the link between households and assets (loans to firms and government debt) and these intermediaries are subject to a reserve requirement. This reserve requirement creates a

\footnotetext{
${ }^{3}$ The dependence of $s(\cdot)$ on $g$ is suppressed since $g$ is held constant throughout the analysis.

${ }^{4}$ This exercise could also be viewed as characterizing the marginal effects of region 1 fiscal policy given the fiscal policy of region 2 .

${ }^{5}$ Thus the budget balance requirement is within a generation and abstracts from any intergenerational transfers.
} 
demand for money even when the return on bonds and loans exceeds the return on money. ${ }^{6}$

The intermediaries take in total deposit, $S=\sum_{i} \eta^{i} s^{i}$, and lend them to firms, $k$, and to the region 1 government, $b$. There is a reserve requirement that a fraction $\lambda$ of the deposit must be held as money. Hence

$$
\frac{M}{p}=\lambda S \quad \text { and } \quad b+k=(1-\lambda) S
$$

The return on deposits $R$ satisfies

$$
R=r(1-\lambda)+\frac{\lambda}{\pi}
$$

where $r$ is, as above, the rental rate on capital, and $\pi$ is one plus the inflation rate. Government bonds, as they compete with loans in the portfolio of the intermediary, must also have a return of $r$.

\subsection{Central Bank}

The Central Bank $(C B)$ controls the supply of money. Changes in the supply of money are brought about through transfers to regional governments and thus to agents in those regions. ${ }^{7}$

Let $T(k, b)$ be the total transfer function of the $C B$ where $k$ is the per capita capital stock in the economy and $b$ is the per capita level of region 1 debt, where $b=\eta^{1} B^{1}{ }^{8}$ We characterize the conduct of monetary policy and its dependence on the aggregate state of the economy, summarized by the state vector $(k, b)$, through this transfer function. We do not consider monetary policy rules dependent upon region specific variables.

In general, both regional governments receive transfers from the $C B$. The region $i$ government receives a transfer of $\phi^{i} T(k, b)$ from the $C B$, where $\phi^{i} \in[0,1]$ and $\sum_{i} \phi^{i}=1$. The transfer $T(k, b)$ is per capita in the federation. Denote by $T^{i}(k, b)$ the transfer per capita made to region $i$ agents: $\eta^{i} T^{i}(k, b)=\phi^{i} T(k, b) .{ }^{9}$

We assume the $C B$ is able to commit to a monetary policy rule, defined by a transfer function, $T(k, b)$, along with the shares, $\left(\phi^{1}, \phi^{2}\right)$. We explore the implications of $T(k, b)$ for the fiscal policy of region 1 . The policy response of the $C B$ noted in the introduction is embedded in the transfer function.

In our analysis, we also emphasize three particular monetary policy rules. The first is an inflation target in which the $C B$ commits to a money growth rate. The second is an interest rate rule in which the $C B$ commits to target an interest rate. ${ }^{10}$ Finally, we study a rule in which the $C B$ pays interest in reserves. For a given rule, we specify the corresponding $T(k, b)$ policy function of the $C B$.

\footnotetext{
${ }^{6}$ The introduction of a reserve requirement follows Smith (1994).

${ }^{7}$ We do not consider open market operations. In some settings, as discussed in Smith (1994) these two forms of monetary operations may not be equivalent.

${ }^{8}$ In the analysis, we use $B^{1}$ when referring to the debt (per member of region 1 ) of a regional government and use $b$ as the debt of region 1 per capita to describe equilibrium objects.

${ }^{9}$ Thus the total transfer is $T(k, b)=\sum_{i} \eta^{i} T^{i}(k, b)$.

${ }^{10} \mathrm{We}$ explore a variety of pegs distinguished by which rate is pegged.
} 


\subsection{Equilibrium Conditions}

We focus on steady state equilibrium of this economy, given a stock of region 1 debt. We then characterize the dependence of the steady state equilibrium on regional debt.

Given a transfer function, $T(k, b)$ and fiscal policy of region $1, b$, a steady state equilibrium satisfies the following conditions:

- Household optimization characterized by the first order condition for a representative region $i$ household:

$$
\begin{gathered}
u^{\prime}\left(c_{y}^{i}\right)=R v^{\prime}\left(c_{o}^{i}\right) \\
c_{y}^{i}=\omega+g^{i}-\tau_{y}^{i}-s^{i}, \quad c_{o}^{i}=R s^{i}-\tau_{o}^{i}
\end{gathered}
$$

for $i=1,2$.

- budget constraint for region $i$ government determining $\tau_{y}^{i}$ and $\tau_{o}^{i}$ from $(k, b)$ :

$$
\frac{b}{\eta^{1}}=g^{1}-\tau_{y}^{1}, \quad \frac{b}{\eta^{1}} r=\tau_{o}^{1}+T^{1},
$$

and

$$
g^{2}=\tau_{y}^{2}=0, \quad \tau_{o}^{2}=-T^{2} .
$$

- factor market equilibrium conditions: $\omega(k)=f(k)-k f^{\prime}(k)$ and $r(k)=f^{\prime}(k)$.

- zero-profit condition for intermediary: $R=(1-\lambda) r(k)+\frac{\lambda}{\pi}$.

Given the assumption of constant returns to scale, the number of producers is not determined in equilibrium. We assume that there is a single firm producing, hiring workers from all regions.

The integration of capital markets implies that in each period, the markets of money, capital rentals, labor and government bonds must clear. The functions $\omega(k)$ and $r(k)$ guarantee that the markets for capital and labor clear at the given levels of factor supply. The market for government bonds will clear as long as the government pays the market clearing rate of interest.

Finally, the rate of inflation is determined by the growth in the money supply which in turn depends on the transfer policy of the $C B$. In particular, the change in the nominal money supply equals the nominal value of the total transfers:

$$
M_{t+1}-M_{t}=p_{t+1} T(k, b) .
$$

Let $\sigma(k, b)$ be defined as one plus the rate of money growth, so

$$
M_{t+1}-M_{t}=(\sigma(k, b)-1) M_{t}
$$


The rate of money growth is linked to the transfer policy by:

$$
T(k, b)=\left(\frac{\sigma(k, b)-1}{\sigma(k, b)}\right)\left(\frac{\lambda}{1-\lambda}\right)(k+b) .
$$

From this, (5) and using $\pi=\sigma$ in steady state, the return on deposits depends on the transfer function,

$$
R(k, b)=\lambda+(1-\lambda)\left(r(k)-\frac{T(k, b)}{k+b}\right) .
$$

Putting these conditions together, we can rewrite the first-order conditions for the households in regions $i=1,2$ as

$$
u^{\prime}\left(\omega(k)+\frac{b}{\eta^{1}}-s^{1}\right)=R(k, b) v^{\prime}\left(R(k, b) s^{1}-r(k) \frac{b}{\eta^{1}}+T^{1}(k, b)\right)
$$

and

$$
u^{\prime}\left(\omega(k)-s^{2}\right)=R(k, b) v^{\prime}\left(R(k, b) s^{2}+T^{2}(k, b)\right) .
$$

These two conditions, since they incorporate the regional governments' budget constraints, factor market clearing and the determination of the return on deposits, are used for the equilibrium analysis. Together, (13)-(15) along with (4) determine the equilibrium values of $\left(s^{1}, s^{2}, k\right)$ given a transfer function, $T(k, b)$, a level of $b$ and $\phi^{i}, i=1,2$.

\section{Equilibrium Analysis}

The analysis characterizes two types of steady state equilibria. The first occurs when the reserve requirement is not binding so that money earns the same return as other assets. In this case, there may be no fiscal spillovers from regional fiscal policy.

The second corresponds to an economy in which the reserve requirement binds. Then, the fiscal policy of one region is not neutral and instead impacts on equilibrium wages and interest rates. That is, there are fiscal spillovers.

\subsection{Non-binding Reserve Requirements}

As a benchmark, we start the analysis by studying economies in which the reserve requirement does not bind. Then, the rates of return on money, capital and bonds must be equal in equilibrium. ${ }^{11}$ In equilibrium, (14) and (15) hold with $R=r$. Since the reserve requirement does not bind, (12) does not hold.

We distinguish two cases: one in which the transfer function depends on $k$ only and a second in which transfers depend directly on $b$. These two cases are economically important. If the $C B$ conditions its policy on $b$, then its response to the fiscal policy of the regional government is direct: changes in the amount of

\footnotetext{
${ }^{11}$ A stationary monetary equilibrium exists in an overlapping generation model with real assets, no productivity growth and no asset markets frictions if and only if the real rate of return on assets in the non-monetary equilibrium is lower than the population growth rate.
} 
regional debt elicits a monetary response. In this case, it is not surprising that fiscal policy of one region has monetary consequences. If, instead, the $C B$ conditions policy only on $k$, then the link between regional fiscal actions and a monetary response will be indirect. This dependence of monetary policy on capital arises from the dependence of wages and interest rates on the capital stock.

As we shall see, when reserve requirements are not binding, fiscal spillovers are absent if the transfer function depends only on $k$. In this case, the only way fiscal spillovers can arise is if they are created by a monetary policy which is directly dependent on $b$.

\subsubsection{Transfer Function Independent of $b$}

Suppose the transfer function depends only on $k$. Any feedback of monetary policy is through variations in $k$ induced by the regional fiscal policy. From the next proposition, the steady state equilibrium is independent of the fiscal policy of region 1 . Thus, in the steady state equilibrium, the transfers are independent of the region 1 policy.

Proposition 1 If $T_{b}(k, b) \equiv 0$, then the steady state equilibrium is independent of $b$.

Proof. The first-order conditions and consumption levels are given by (14) and (15). At a monetary steady state equilibrium with a non-binding reserve requirement, $R(k, b)=r(k)$. With the assumption of $T_{b}(k, b) \equiv 0$, the only impact of region 1 fiscal policy on these conditions is through the term $\frac{b}{\eta^{1}}$ in (14). In particular, $T^{1}$ and $T^{2}$ do not depend on $b$ by assumption, and $r(k)=\frac{1}{\sigma}=1-\frac{T}{Q}$ where $Q$ is real money balances. Accordingly, the first-order condition for region 1 agents determines only the difference between saving and bonds in that region, $\left(s^{1}-\frac{b}{\eta^{1}}\right)$. Real money balances, $Q=\eta^{1} s^{1}+\eta^{2} s^{2}-k-b$, do not depend on $b$ as $\left(s^{1}-\frac{b}{\eta^{1}}\right)$ is invariant to $b$. Thus variations in region 1 debt are matched by variations in the saving of that region.

This is a standard Ricardian result. Essentially region 1 conducts fiscal policy in isolation from region 2 and from the $C B$. Variations in taxes set in youth influence the level of debt and taxes in the future. Households in region 1 fully anticipate the link between current and future taxes and adjust savings accordingly. There are no equilibrium effects of region 1 fiscal policy. That is, equilibrium interest rates and wages are independent of $\frac{b}{\eta^{1}}$. In equilibrium the transfers of the $C B$ are independent of the fiscal policy of region 1 .

\subsubsection{Transfer Function Dependent on $b$}

Consider $T_{b}(k, b) \neq 0$ so the $C B$ is induced to respond to region 1 fiscal policy directly. That is, even if region 1 policy has no direct effect on the capital stock, the $C B$ responds directly to variations in $b$. Given this direct dependence of monetary policy on the per capita debt in the economy, it is not surprising that the steady state depends on the fiscal policy stance of region 1.

Proposition 2 If $T_{b}(k, b) \neq 0$, then the steady state equilibrium depends upon $b$.

Proof. The conditions for equilibrium at the steady state are given by (14) and (15).

The equilibrium determines $\left(s^{1}-\frac{b}{\eta^{1}}, s^{2}, k\right)$. By assumption, $T^{1}(k, b)$ and $T^{2}(k, b)$ vary with $b$, given $k$. Hence (14) and (15) cannot hold at different values of $b$ if $\left(s^{1}-\frac{b}{\eta^{1}}, s^{2}, k\right)$ remains unchanged. 
There are equilibrium effects of region 1 fiscal policy through a $C B$ rule in which $T_{b}(k, b) \neq 0$. If this was the only link between regions, a policy of limiting fiscal spillovers would be simple: the $C B$ should adopt a rule in which $T_{b}(k, b) \equiv 0$.

\subsection{Binding Reserve Requirements}

In this section, we study an economy in which the reserve requirement is binding. This friction in asset markets breaks the equalization of returns on money and other assets and will lead to a couple of important findings. First, Ricardian equivalence fails: the fiscal policy choice of region 1 will have real effects on the capital stock and thus on wages and interest rates. Second, unless the $C B$ adopts a rule in which $T(k, b)$ is independent of $(k, b)$, the fiscal policy of region 1 will induce a monetary policy response.

We study steady state equilibria with valued fiat money given the transfer function of the $C B$ and the fiscal policy of region 1 . We compare steady states for different levels of debt issued by region $1 .{ }^{12}$

Our starting point for the analysis is to study the case in which the $C B$ commits not to make any transfers, $T(k, b) \equiv 0$. This case is useful as it highlights the existence of fiscal spillovers: the impact of region 1 fiscal policy on the steady state even for an inactive monetary authority.

Proposition 3 For $T(k, b) \equiv 0$, the steady state equilibrium is dependent on $b$.

Proof. To see that region 1 fiscal policy does impact the steady state equilibrium, we assume that it does not and reach a contradiction. Suppose the region 1 government alters the level of taxes in youth and thus changes the level of debt it issues: $\Delta \frac{b}{\eta^{1}}=-\Delta \tau_{y}^{1}$. If this change in fiscal policy was neutral, then $R$ would not change since, from (13), $R$ does not depend on $b$ when $T(k, b) \equiv 0$. In that case, region 1 agents would simply adjust their savings with the change in taxes. The change in aggregate saving would be given by $\Delta S=\eta^{1} \Delta \frac{b}{\eta^{1}}$, where $\eta^{1}$ is again the size of the region 1 population. Using $b+k=(1-\lambda) S$, $\Delta k=(1-\lambda) \Delta S-\Delta b$. If the only change in aggregate saving is due to the change in region 1 debt, then $\Delta S=\Delta b$ implies $\Delta k=(1-\lambda) \Delta b-\Delta b=-\lambda \Delta b \neq 0$ when $\lambda>0$. This contradicts the construction of an equilibrium with neutral fiscal policy.

Changes in $b$ will thus affect $k$ and hence the real interest rate and the real wage rate. The consumption profile of region 2 agents is characterized by (14) and (15). Variations in $\omega$ and $R$ induced by the fiscal policy of region 1 will alter the consumption levels and welfare of region 2 agents. The equilibrium allocation is not independent of $\frac{b}{\eta^{1}}$.

This proposition makes clear that the Ricardian result is not robust to the introduction of reserve requirements. Given the differential in return between household saving and the interest on government debt, $r>R$, the dependence of the steady state on region 1 fiscal policy is not surprising.

We study the local dynamics of the capital stock to determine the response of the economy to a change in the debt of region 1 . We do so in the neighborhood of a locally stable steady state with $T(k, b)=0$ so, from $(12), \sigma(k, b)=1$. However, we now allow transfers to vary in response to changes in $(k, b)$.

\footnotetext{
${ }^{12}$ We use local dynamics only to obtain signs for comparative statics. Understanding how the transfer function of the $C B$ influences local dynamics is a topic for further study.
} 
Proposition 4 If $\frac{d k_{t+1}}{d k_{t}} \in(0,1)$ at the steady state and $T_{b}(k, b) \geq 0$, then $\frac{d k}{d b}<0$.

\section{Proof.}

The dynamic equation for the capital stock is:

$$
k_{t+1}=(1-\lambda) \sum_{i} \eta^{i} s^{i}\left(\omega\left(k_{t}\right), R\left(k_{t+1}, b\right), \tau_{y}^{i}, \tau_{o}^{i}\left(k_{t+1}, b\right)\right)-b .
$$

where $s^{i}\left(\omega, R, \tau_{y}^{i}, \tau_{o}^{i}\right)$ is the savings function for a region $i$ agent given factor prices and taxes from (6). Here $\tau_{o}^{1}\left(k_{t+1}, b\right)=\frac{r\left(k_{t+1}\right) b}{\eta^{1}}-T^{1}\left(k_{t+1}, b\right)$ and $\tau_{o}^{2}\left(k_{t+1}, b\right)=-T^{2}\left(k_{t+1}, b\right)$ as in $(8)$.

Capital dynamics are governed by:

$$
\frac{d k_{t+1}}{d k_{t}}=\frac{(1-\lambda) \sum_{i} \eta^{i} s_{\omega}^{i} \omega^{\prime}\left(k_{t}\right)}{1-(1-\lambda)\left[\sum_{i} \eta^{i}\left(s_{R}^{i} R_{k}\left(k_{t+1}, b\right)+s_{\tau_{o}}^{i} \frac{\partial \tau_{o}^{i}\left(k_{t+1}, b\right)}{\partial k}\right)\right]} .
$$

From the region 1 budget constraint, the tax when old depends on the capital stock as well as the transfers from the $C B .^{13}$ Thus, using (8) and (9), $\frac{\partial \tau_{o}^{1}\left(k_{t+1}, b\right)}{\partial k}=\frac{r^{\prime}\left(k_{t+1}\right) b}{\eta^{1}}-T_{k}^{1}\left(k_{t+1}, b\right)$ and $\frac{\partial \tau_{o}^{2}\left(k_{t+1}, b\right)}{\partial k}=-T_{k}^{2}\left(k_{t+1}, b\right)$.

The proposition assumes that the steady state is locally stable: $\frac{d k_{t+1}}{d k_{t}} \in(0,1)$ at the steady state. If the $C B$ is not responsive to variations in the capital stock, $T_{k}(k, b) \equiv 0$, then $\frac{d k_{t+1}}{d k_{t}}<1$ iff

$$
(1-\lambda)\left(\sum_{i} \eta^{i}\left(s_{\omega}^{i} \omega^{\prime}\left(k_{t}\right)+s_{R}^{i} R_{k}\left(k_{t+1}, b\right)\right)+s_{\tau_{o}}^{1} r^{\prime}\left(k_{t+1}\right) b\right)<1 .
$$

As in the standard Diamond (1965) model, this inequality must be assumed to hold at a steady state.

With $T_{k}(k, b) \equiv 0, \frac{\partial \tau_{o}^{1}\left(k_{t+1}, b\right)}{\partial k}=\frac{r^{\prime}\left(k_{t+1}\right) b}{\eta^{1}}<0$ and $\frac{\partial \tau_{o}^{2}\left(k_{t+1}, b\right)}{\partial k}=0$. Using $s_{\tau_{o}}^{i}>0$ from consumption smoothing, and the assumptions that $s_{R}^{i}>0$ and $s_{\omega}^{i}>0$, the numerator and the denominator of (17) are positive so that $\frac{d k_{t+1}}{d k_{t}}>0$. From this and assuming (18) holds, $\frac{d k_{t+1}}{d k_{t}} \in(0,1)$ in the neighborhood of the steady state.

In general we will allow $T_{k}(k, b) \neq 0$. If $T_{k}(k, b) \geq 0$, then from $(13), R_{k}(k, b)=(1-\lambda)\left[r^{\prime}(k)-\frac{T_{k}(k, b)}{k+b}-\right.$ $\left.\frac{T(k, b)}{(k+b)^{2}}\right]<0$. Therefore, the denominator of (17) remains positive, using $s_{\tau_{o}}^{i}>0$. Hence, we will have $\frac{d k_{t+1}}{d k_{t}}>0$. This along with $(18)$ implies $\frac{d k_{t+1}}{d k_{t}} \in(0,1)$.

The effect of a change in the level of region 1 debt on the steady state capital stock is:

$$
\frac{d k}{d b}=\frac{-\left[1-(1-\lambda) \sum_{i} \eta^{i}\left(s_{\tau_{y}}^{i} \frac{d \tau_{y}^{i}}{d b}+s_{\tau_{o}}^{i} \frac{d \tau_{o}^{i}}{d b}+s_{R}^{i} R_{b}(k, b)\right)\right]}{1-(1-\lambda)\left[\sum_{i} \eta^{i}\left(s_{R}^{i} R_{k}(k, b)+s_{\omega}^{i} \omega^{\prime}(k)+s_{\tau_{o}}^{i} \frac{\partial \tau_{o}^{i}(k, b)}{\partial k}\right)\right]} .
$$

The denominator of (19) is positive based on local stability. From (8) and (9), $\frac{d \tau_{y}^{1}}{d b}=\frac{-1}{\eta^{1}}, \frac{d \tau_{o}^{1}}{d b}=\frac{r}{\eta^{1}}-T_{b}^{1}(k, b)$, $\frac{d \tau_{y}^{2}}{d b}=0$ and $\frac{d \tau_{o}^{2}}{d b}=-T_{b}^{2}(k, b)$. We use this to evaluate the numerator of (19). We find:

\footnotetext{
${ }^{13}$ As the capital stock evolves, we assume that the regional government budget constraint is met by changes in taxes on agents in old age only.
} 


$$
\begin{array}{r}
-\left[1-(1-\lambda) \sum_{i} \eta^{i}\left(s_{\tau_{y}}^{i} \frac{d \tau_{y}^{i}}{d b}+s_{\tau_{o}}^{i} \frac{d \tau_{o}^{i}}{d b}+s_{R}^{i} R_{b}(k, b)\right)\right] \\
=-\left[1-(1-\lambda)\left(-s_{\tau_{y}}^{1}+s_{\tau_{o}}^{1}\left(r-T_{b}^{1}(k, b) \eta^{1}\right)+(1-\lambda) \eta^{2} T_{b}^{2}(k, b) s_{\tau_{o}}^{2}-(1-\lambda)\left(\eta^{1} s_{R}^{1}+\eta^{2} s_{R}^{2}\right) R_{b}(k, b)\right]\right. \\
=-\left[1-(1-\lambda)\left(-s_{\tau_{y}}^{1}+s_{\tau_{o}}^{1} r\right)+\Gamma\right] \\
=-\left[\lambda-s_{\tau_{o}}^{1} \lambda\left(R-\frac{1}{\sigma}\right)+\Gamma\right] \\
=-\left[\lambda\left(1-s_{\tau_{o}}^{1} R\right)+\lambda s_{\tau_{o}}^{1}\left(\frac{1}{\sigma}\right)+\Gamma\right]
\end{array}
$$

where $\left.\Gamma=(1-\lambda)\left[s_{\tau_{o}}^{1} T_{b}^{1}(k, b) \eta^{1}+s_{\tau_{o}}^{2} T_{b}^{2}(k, b) \eta^{2}-\left(\eta^{1} s_{R}^{1}+\eta^{2} s_{R}^{2}\right) R_{b}(k, b)\right]\right]$. As noted earlier, $s_{\tau_{o}}^{i}>0, s_{R}^{i}>0$ and $R_{b}(k, b)<0$ from (13) at $T(k, b)=0$. Thus $\Gamma>0$.

From the household's optimization problem, $R s_{\tau_{o}}-s_{\tau_{y}}=1$ along with $s_{\tau_{y}}<0$ and $s_{\tau_{o}}>0$. Hence, $\left(1-s_{\tau_{o}}^{1} R\right)=-s_{\tau_{y}}^{1}>0$.

If $T_{b}(k, b) \geq 0$, the numerator of (19) is negative as each of the three terms inside the bracket is positive. Hence $\frac{d k}{d b}<0$.

This result provides sufficient conditions for the spillover of debt by $R G^{1}$ to reduce the steady state capital stock. Crowding out in this case is, in fact, somewhat counter-intuitive.

If a household earns a return of $R$ on its saving and the return on debt is $r$ where $r>R$, then an increase in government debt will lead the household to save more than the increase in $b$. In this way, the household smoothes consumption in the face of the increased tax burden in old age. This expected 'crowding-in' result is not what we get in Proposition 4.

Our model delivers a different result because of the binding reserve requirement. There are two consequences of $\lambda>0$. The first, as noted already, creates $r>R$. The second, as is seen in the capital accumulation equation (16) is that only a fraction of saving goes into the accumulation of capital. It is this second effect which is key to the result. While a household may want to increase saving beyond the increase in debt when $r>R$, the presence of the reserve requirement means that a portion of this extra saving is in the form of real money and not capital. Thus we obtain a crowding out result.

This proposition assumes $T_{b}(k, b) \geq 0$. If instead $T_{b}(k, b)<0$, an increase in region 1 debt would induce a reduction in transfers. Anticipating this, young region 1 agents will choose to save more in anticipation of higher future taxes. If this response is large enough, the crowding out effect could be overturned.

Included in the proposition is the assumption of local stability in order to sign the effect of debt on the steady state capital stock. In this economy, local stability depends, as usual, on the properties of $s(\cdot)$ and also on the transfer function. As is clear from (17), the dynamics of the capital stock depend upon $T_{k}(k, b)$. Thus another avenue for influence of the $C B$ is through capital dynamics in the neighborhood of the steady state.

\section{Insulation Impossible}

Proposition 4 indicates that an increase in region 1 debt can lead to a reduction in the capital stock and thus influence the wage rate and rate of return of region 2 agents. In this way, there are spillover effects. Moreover, 
these effects also work through the transfer function, $T(k, b)$, of the monetary authority. Proposition 4 relied on some properties of these transfer functions in order to obtain crowding out.

Now we look at the transfer functions from a different perspective. Can the choice of a transfer function insulate region 2 from the fiscal policy of region 1? As noted in our introductory comments, one interpretation of EMU policy design has been to construct fiscal and monetary policies to minimize fiscal spillovers.

Taking this as given, does there exist a $C B$ policy, $\left(T(k, b), \phi^{1}, \phi^{2}\right)$, which completely eliminates the fiscal spillover highlighted by Proposition 3? That is, do there exist transfer functions which insulate the consumption and thus utility of region 2 agents from the fiscal policy of region 1? And, more generally, are there transfer functions which can neutralize the effects of region 1 fiscal policy on the consumption levels of all agents as well as the capital stock? We answer both questions in the same way: such insulation is impossible. ${ }^{14}$ This remains true even if we broaden monetary policy to allow for two independent transfer functions, $T^{i}(k, b)$ for $i=1,2$ instead of restricting monetary policy to make transfers according to the fixed shares, $\left(\phi^{1}, \phi^{2}\right)$.

Proposition 5 There does not exist a monetary policy, $\left(T(k, b), \phi^{1}, \phi^{2}\right)$, such that the steady state equilibrium levels of consumption of region 2 agents, $\left(c_{y}^{2}, c_{o}^{2}\right)$, are independent of $b$.

Proof. From the first-order condition of region 2 agents, (15), their consumption levels, $\left(c_{y}^{2}, c_{o}^{2}\right)$, are independent of $b$ iff both $R(k, b)$ and their lifetime income are independent of $b$. By independent of $b$ we mean independent of the direct effects of changes in $b$ and the effects of changes in $b$ on the steady state equilibrium value of $k$.

From $R(k, b)=\lambda+(1-\lambda)\left(r(k)-\frac{T(k, b)}{k+b}\right), R(k, b)$ is independent of $b$ iff $\left(r(k)-\frac{T(k, b)}{k+b}\right)$ is independent of $b$. For that to be the case at a steady state with zero inflation, $(T(k, b)=0)$, the following must hold:

$$
r^{\prime}(k) k_{b}=\frac{T_{b}(k, b)+T_{k}(k, b) k_{b}}{k+b}
$$

where $k_{b}$ is the change in the steady state capital as $b$ changes.

Further, given a portfolio return that does not depend on $b,\left(c_{y}^{2}, c_{o}^{2}\right)$ are independent of $b$ if the discounted present value of lifetime income and transfers, $\omega(k)+\frac{T^{2}(k, b)}{R}$ is independent of $b$. This implies that

$$
\omega^{\prime}(k) k_{b}+\frac{\frac{\phi^{2}}{\eta^{2}}\left[T_{b}(k, b)+T_{k}(k, b) k_{b}\right]}{R}=0
$$

where we have used $\frac{\phi^{2}}{\eta^{2}} T(k, b)=T^{2}(k, b)$.

Using $\omega(k)=f(k)-k f^{\prime}(k)$ and $r(k)=f^{\prime}(k),-\omega^{\prime}(k)=k r^{\prime}(k)$. This condition, along with the substitution of $T_{b}(k, b)+T_{k}(k, b) k_{b}$ from (20) into (21), implies

$$
k=\left(\frac{\phi^{2}}{\eta^{2}}\right) \frac{k+b}{R}
$$

so that

\footnotetext{
${ }^{14}$ As with Proposition 4 , these results hold in the neighborhood of a locally stable steady state with $\sigma(k, b)=1$.
} 


$$
k=\frac{\left(\frac{\phi^{2}}{\eta^{2} R}\right) b}{1-\frac{\phi^{2}}{\eta^{2} R}} .
$$

This condition implies that the steady state level of the capital stock is increasing in the stock of region 1 debt.

If $R(k, b)$ is independent of $b$, then $T_{b}(k, b)=\frac{\lambda}{1-\lambda} \frac{\sigma-1}{\sigma}=0$ at a locally stable steady state with no money growth. Thus Proposition 4 holds. The fact that $k$ is increasing in $b$, from (23), contradicts the crowding-out of that proposition.

Thus if the monetary authority takes as its goal to stabilize the consumption of region 2 agents in the face of variations in the fiscal policy of region 1, it does not have the power to do so: insulation impossible. To do so, the monetary authority would have to stabilize both the return on deposits and the lifetime income of region 2 agents. But evidently that policy is not able to offset variations in $\omega(k)$ and thus stabilize lifetime income of region 2 agents.

Proposition 5 refers to the impossibility of insulating the consumption levels of region 2 agents from variations in $b$. There is a closely related result that there does not exist a monetary policy which can offset the real effects of region 1 debt on agents in both regions. This is a generalization of Proposition 3: the lack of Ricardian equivalence reported in that proposition cannot be offset by an appropriately chosen monetary policy of $\left(T(k, b), \phi^{1}, \phi^{2}\right)$.

In fact, there is a stronger result. Even if we allow monetary policy to be determined by two independent transfer functions, $T^{i}(k, b)$ for $i=1,2$, insulation of the consumption of all agents along with the capital stock is still impossible.

Proposition 6 There do not exist $T^{i}(k, b)$ transfer functions, for $i=1,2$, such that the steady state equilibrium levels of consumption for agents in regions $i=1,2$ and the capital stock are independent of $b$.

Proof. In equilibrium, the first-order conditions for region $i$ agents are given by (14) and (15). These are:

$$
u^{\prime}\left(\omega+\frac{b}{\eta^{1}}-s^{1}\right)=R v^{\prime}\left(R s^{1}-r \frac{b}{\eta^{1}}+T^{1}(k, b)\right)
$$

and

$$
u^{\prime}\left(\omega-s^{2}\right)=R v^{\prime}\left(R s^{2}+T^{2}(k, b)\right) .
$$

Suppose, to the contrary, that there exist transfer functions $T^{i}(k, b)$ such that the steady state consumption levels of all agents and the capital stock are independent of $b$. From (25), the consumption levels of region 2 agents would be independent of $b$ iff both $R$ and $T^{2}(k, b)$ are independent of $b$.

With $R=r(k)(1-\lambda)+\frac{\lambda}{\sigma}$, if $R$ and $k$ are independent of $b$, then $\sigma$ must be as well. The growth rate of the money supply is related to the transfer function by

$$
T(k, b)=\frac{\lambda(k+b)}{1-\lambda} \tilde{\sigma}
$$

where $\tilde{\sigma} \equiv \frac{\sigma-1}{\sigma}$ and $T(k, b)=\sum_{i} \eta^{i} T^{i}(k, b)$. If (26) holds for all $b$, given $(k, \sigma)$, then 


$$
\eta^{1} T_{b}^{1}(k, b)=\frac{\lambda}{1-\lambda} \tilde{\sigma}
$$

At the steady state with no money growth, $\tilde{\sigma}=0$. Hence $T_{b}(k, b)=0$.

For the consumption of region 1 agents to be independent of $b,(24)$ must hold for all $b$. From this condition, if $c_{y}^{1}$ is independent of $b$ then so must $\frac{b}{\eta^{1}}-s^{1}$. In order for $c_{o}^{1}$ to be independent of $b$,

$$
(R-r) \frac{b}{\eta^{1}}+T^{1}(k, b)
$$

must be independent of $b$. For (28) to hold for all $b$, it follows that

$$
\eta^{1} T_{b}^{1}(k, b)=-(R-r)
$$

Since the reserve requirement is binding in the steady state, $R<r$ so $T_{b}^{1}(k, b)>0$.

Equations (27) and (29) are two conditions on the derivative of the same transfer function in response to variations in $b$. These conditions are inconsistent. Thus the consumption levels of agents in both regions are not independent of $b$.

Taken together, Propositions 5 and 6 show that the effects of region 1 fiscal policy cannot be offset by a monetary policy rule. Essentially, even a general monetary policy rule consisting of two independent transfer functions is not enough to provide insulation. There are two spillover channels at work in a monetary union. The first one is linked to the remuneration of production factors, which depends on the amount of debt circulating in the economy. The other is linked to the monetary transfers to regional governments, associated with the implementation of a money policy rule.

A monetary rule generally depending on $k$ and $b$ implies transfers. There is no rule such that these transfers do not affect the macroeconomic outcome of the union and thus the welfare in any region: one spillover channel cannot be used to nullify the other one. This is the essence of the insulation impossible result.

Note that while the model is cast with only a single active region, the results reflect the marginal effects of regional debt. Thus, if the multiple regions were pursuing independent fiscal policies, our results would still hold: the monetary authority would be unable to design a transfer function to insulate agents from the fiscal policy choices of any single region.

\section{$5 \quad$ Fiscal Policy Under Specific Monetary Policy Rules}

One might argue that a typical $C B$ does not operate through the state contingent transfer functions studied thus far. Accordingly, we focus on some particular, more familiar, policy rules. The objective is to understand how these rules are nested in our framework and to evaluate their influence on fiscal spillovers.

The first policy rule of interest is inflation targeting. In our model, this is equivalent to fixing the growth rate of the nominal money supply. Since the level of real money demand is endogenous, this policy is not 
equivalent to fixing the growth rate of the real money stock. Thus, as we shall see, variations in regional debt will lead to policy responses.

The second policy rule pegs the return on deposits. While this policy has the advantage of insulating interest rates from regional debt, it has other consequences since the process of pegging an interest rate requires transfers to the regional governments. By focusing on these two types of rules, we are able to highlight the indirect effects of monetary interventions.

We also look at a third policy of paying interest on reserves. ${ }^{15}$ This is of interest given the importance of a binding reserve requirement for our analysis. If the payment of interest on reserves can relax the reserve requirement, then regional fiscal policy might become neutral and thus one region could be insulated from the other.

In this analysis, we continue to assume that the steady state is locally stable. In this way, our results build upon the crowding-out result of Proposition 4.

\subsection{Inflation Target}

In our model, an inflation target is equivalent to the choice of a fixed money growth rule, denoted a $\sigma-$ rule. Here we assume a non-negative inflation target, in keeping with usual $C B$ practice. We then discuss deflation below in the context of paying interest on reserves.

From (12), the transfers required to support a given growth rate in the money supply are given by

$$
T(k, b)=\lambda S \frac{(\sigma-1)}{\sigma}=\frac{\lambda(k+b)}{(1-\lambda)} \tilde{\sigma}
$$

where $\tilde{\sigma} \equiv \frac{\sigma-1}{\sigma}$ is the policy choice. From (30), the rate of money growth determines the transfer policy of the $C B .^{16}$

For this case, $\left.T_{k}(k, b)\right)=\frac{\lambda}{(1-\lambda)} \tilde{\sigma}>0$. So, as noted earlier, if the Diamond conditions for stability hold, then $\frac{d k_{t+1}}{d k_{t}} \in(0,1)$ at the steady state.

With this specific policy, we find, following Proposition 4, there is crowding out:

Corollary 1 Under a $\sigma$-rule with $\tilde{\sigma} \geq 0$, an increase in $b$ leads to a reduction in the capital stock, an increase in the real interest rate and a reduction in the real wage.

\section{Proof.}

From $\left.(30), T_{b}(k, b)\right)=\frac{\lambda}{(1-\lambda)} \tilde{\sigma}$. This is positive if $\tilde{\sigma} \geq 0$ so Proposition 4 holds.

When the monetary authority follows a constant money growth rate policy, an increase in the debt of region 1 has the traditional crowding out effect of reducing the capital stock. Though this fiscal policy of region 1 does not directly effect region 2 agents, the change in the capital stock leads to changes in real wages and interest rates. These price changes do impact on region 2 agents.

\footnotetext{
${ }^{15}$ We are grateful to Kevin Lansing for questions and discussions of this issue.

${ }^{16}$ Importantly, this is not the same policy as $T(b, k) \equiv 0$, except when $\sigma=1$. Else, a fixed money growth rule creates new money and the level of real transfers depends on $(k, b)$.
} 
In addition, even though the $C B$ is fixing the money growth rate, real transfers are influenced by $(k, b)$ from (30). As a consequence, fiscal actions in region 1 impact $(k+b)$ and thus real transfers to region 2 unless $\phi^{2}=0$.

Again, referring to the European experience of the post-2008 crisis, it is clear that a Central Bank which operates with an inflation target, like the ECB, may be induced to increase real transfers and thus add liquidity when a country raises its level of public expenditures and indebtedness for stabilization purposes. This is what has happened in 2009 and 2010 when European countries benefited de facto from large ECB purchases of bonds of various countries, as part of its quantitative easing program.

In our model, if $(k+b)$ is increasing in $b$, then an increase in $b$ will, from (30), increase real transfers. Thus a commitment by the $C B$ to an inflation target does not preclude state dependent variations in real transfers which accommodate fiscal expansions.

Another avenue is through increased demand for real money balances due to increased uncertainty in the intermediation process. In this case, a fixed nominal money growth target will imply a higher level of real transfers. The $C B$ will again be accommodating even though it operates with an inflation target.

\section{$5.2 \quad$ Interest Rate Targets}

To eliminate this fiscal interaction, a $C B$ may choose to peg an interest rate, denoted $R$-rule. The value of a peg may be to insulate interest rates from the effects of regional debt. This type of policy is often thought of as the monetization of debt. While the $C B$ can certainly act to offset the effects of regional debt on interest rates, it is not be able to insulate region 2 agents from region 1 fiscal policy.

In this economy there are a number of candidate interest rates to target. We start with a peg of the real return on saving and then discuss alternatives.

\subsubsection{Pegging the Real Return on Deposits}

We consider a $C B$ policy to peg the interest rate on deposits, $R$, by making money transfers to the region 1 government. With this policy the central bank is indeed "weak": it is forced to respond to the fiscal policy of region 1.

To understand this policy, recall that in equilibrium the return $R$ is given by

$$
R=r(k)(1-\lambda)+\frac{\lambda}{\sigma}
$$

If the $C B$ pegs $R$, then the rate of money growth is set such that (31) holds for all $k$. This makes the rate of money growth dependent on $k$ but independent of $b$. From (30), $C B$ transfers are then determined by the $\sigma(k)$ rule that pegs $R$.

Corollary 2 Under a $R$-rule pegging $R$, if $\tilde{\sigma} \geq 0$, an increase in $b$ leads to a reduction in the capital stock and an increase in the rate of inflation.

\section{Proof.}


From $(30), T_{b}(k, b)=\frac{\lambda}{(1-\lambda)} \tilde{\sigma}$ since $\tilde{\sigma}$ does not vary with $b$. This is positive if $\tilde{\sigma} \geq 0$ so Proposition 4 holds. Hence as $b$ increases, $k$ falls.

The reduction in $k$ leads to an increase in $r$. In order for $R$ to remain unchanged, the rate of money creation must be higher, from (31). In steady state, the rate of inflation will be higher.

Under this monetary policy rule, region 1 debt affects both the capital stock and the rate of inflation. Increased debt of region 1 is inflationary. The inflation is caused by the response of the $C B$ to the increased interest rate caused by the debt of a region.

In this case, region 1 debt spills over to region 2 agents through two channels: the direct effect of $b$ on $k$ and the induced transfers from the $C B$. Though the pegging of $R$ does not neutralize the effects of region 1 debt on region 2 households, it can isolate those effects. This policy insulates the agents in region 2 from the inflation tax induced by the fiscal policy of region 1 .

Region 2 can be further insulated if $\phi^{2}=0$ so that all transfers go to the region 1 government. This restriction along with the pegging of $R$ implies that region 2 agents are affected by $b$ only through equilibrium wages. Once $R$ is set, the consumption of region 2 agents solves (6) with $c_{y}^{2}=\omega(k)-s^{2}$ and $c_{o}^{2}=R s^{2}$. While variations in $\frac{b}{\eta^{1}}$ will induce a response by the monetary authority, the consumption levels in region 2 are not influenced by the inflation tax since $R$ is independent of $\frac{b}{\eta^{1}}$ and $\phi^{2}=0$. As before, the wage of region 2 agents in youth will be affected by $k$.

\subsubsection{Pegging the Return on Capital}

We focused on the peg of $R$ since that policy provides insulation from the inflation tax for region 2 agents from the policy of region 1. It does so by fixing the return on saving. But, as we have seen, the level of capital and hence the wage rate varies with region 1 debt.

Alternatively, the $C B$ could take action to peg $r$. In this case, the capital stock will clearly be independent of $b$. But there are other effects of changes in $b$.

Proposition 7 Under a $R$-rule pegging $r, k$ is independent of $b$. Further, increases in $b$ will increase the return on saving and lower the rate of inflation.

\section{Proof.}

If the $C B$ pegs the real return on capital, this implies that the capital stock and thus wages are independent of the fiscal policy in region 1. This insulates region 2 from any effects of region 1 debt on the capital stock and thus on wages. But, in order for the increased region 1 debt to be purchased, the return on saving, $R$, must increase. Given a fixed $r$, the increase in $R$ arises from a lower rate of inflation and thus a lower rate of money creation. This lower inflation and higher $R$ will impact on region 2 agents.

\subsection{Relaxing the Reserve Requirement}

Given that the fiscal policy of region 1 matters only if the reserve requirement binds, it is natural to consider monetary policy rules which relax the reserve requirement. Equivalently, one can look at policies such that the rate of deflation is large enough to equalize the rates of return on money and capital. This section studies 
the payment of interest on reserves. As we shall see, the outcome is not the same as the equilibrium without reserve requirements.

While it is beyond the scope of this paper to undertake a complete analysis of the equilibria with interest on reserves, our discussion serves two purposes. First, we argue that a policy of paying interest on reserves fits into our general framework. Second, we can extend our results on insulation impossible to conclude that the payment of interest on reserves is not sufficient to neutralize the fiscal policy of region 1.

Suppose the $C B$ chooses to pay a nominal interest of $\rho$ on reserves. Following Freeman and Haslag (1996), we assume that the interest paid to the intermediaries is financed through taxation. In our setting with regional governments, the $C B$ "taxes" the regional governments to finance interest on reserves through the transfer function, $T(k, b)$. The regional governments pass these obligations to the households.

With this modification to our model, the interest rate paid to depositors is given by:

$$
R(k, b)=(1-\lambda) r(k)+\lambda \frac{(1+\rho)}{\pi} .
$$

In steady state, the $C B$ pays out interest of $\rho \lambda S$, as $\lambda S$ is real money demand by the intermediaries as $S \equiv \sum^{i} \eta^{i} s^{i}$ is total saving. Thus the total tax levied on the regional governments must be enough to finance this transfer (which is actually a tax since it is negative), $T(k, b)=-\rho \lambda S$. The tax depends on $(k, b)$ since total savings, $S=\frac{k+b}{1-\lambda}$, implying $T(k, b)=-\rho \lambda \frac{k+b}{1-\lambda}$.

The budget constraints of the regional governments are modified to

$$
r \frac{b}{\eta^{1}}=\tau_{o}^{1}-\phi^{1}\left(\rho \lambda \frac{k+b}{1-\lambda}\right)
$$

and

$$
\phi^{2}\left(\rho \lambda \frac{k+b}{1-\lambda}\right)=\tau_{o}^{2}
$$

These constraints are the same as (8) and (9) except that now there is a transfer from the regional governments to the $C B$ in order to finance the interest payment on reserves. Of course, as indicated by these two budget constraints, the tax on the regional government by the $C B$ appears as a tax on old households, as in Freeman and Haslag (1996).

With these flows, the steady state consumption of old agents in regions 1 and 2 become:

$$
c_{o}^{1}=s^{1} R-\frac{b r}{\eta^{1}}-\frac{\phi^{1}}{\eta^{1}} T(k, b)=s^{1} R-\frac{b r}{\eta^{1}}-\frac{\phi^{1} \rho \lambda S}{\eta^{1}}
$$

and

$$
c_{o}^{2}=s^{2} R-\frac{\phi^{2}}{\eta^{2}} T(k, b)=s^{2} R-\frac{\phi^{2} \rho \lambda S}{\eta^{2}} .
$$

These consumption levels in old age have the same structure as consumption in old age in (14) and (15). There is only a difference in the sign of the transfer since the transfer is from the households to the regional government and then to the $C B$. 
Since $T(k, b)=-\rho \lambda \frac{k+b}{1-\lambda}$, except for the sign of the transfer, the monetary transfers underlying the payment of interest on reserves fits into our general framework. In fact, the allocation is analogous to one with a negative inflation target, i.e. deflation. ${ }^{17}$

In addition, we can extend the logic of Freeman and Haslag (1996) to understand the properties of the equilibrium with interest on reserves. One of the interesting points in Freeman and Haslag (1996) is that the choice of the interest rate on reserves has a substitution but no income effect. This is because the payment of interest on reserves eventually flows to the same households who pay the tax to finance this payment. In the multiple region economy, there is the potential for redistribution because of the sharing of the tax obligation through $\left(\phi^{1}, \phi^{2}\right)$.

Finally, the payment of interest on reserves is not enough to "undo" the reserve requirement and return to the case of a non-binding constraint. Even in the one region model of Freeman and Haslag (1996), if the government pays interest on reserves equal to the return on physical capital, thus appearing to overcome the reserve requirement, the tax obligation of the household's reflects the reserve requirement. So, in the end, the allocation is still not identical to that arising from a model without any reserve requirement.

For our multi-region model, the analogue of that result is that insulation is not possible, even with the payment of interest on reserves. We see that from the fact that our earlier results, Propositions 5 and 6 , cover this policy as well.

\section{Market Segmentation}

Our model economy has thus far assumed the free flow of capital and intermediated activity across the regions. We have focused on how the design of monetary policy influences spillovers across regions. It is interesting to study the interrelationship between fiscal spillovers and market segmentation in which there are barriers to the flows of financial and physical capital. As we shall see, these barriers can themselves provide some insulation and can also influence the impact of monetary policy.

\subsection{Financial Market Segmentation}

From Corollaries 1 and 2, it appears that a peg of the return on deposits limits the fiscal spillovers compared to a $\sigma$-rule. The point of this section is to illustrate that those results are quite sensitive to the assumed capital market structure. To make this point, we consider an extreme version of our multi-region economy in which a subset of agents hold money directly, rather than going to the intermediary.

In particular, we assume that only region 1 agents have access to intermediaries. Region 2 agents just hold money. This can be rationalized through the existence of costs of accessing intermediaries which differ across regions. ${ }^{18}$

\footnotetext{
${ }^{17}$ One can formally show the equivalence of the outcomes under deflation and the payment of interest on reserves in this environment.

${ }^{18}$ Allowing access to both forms of savings by some agents in both regions is also of interest. One could also imagine a model with endogenous market segmentation along the lines of Chatterjee and Corbae (1992). Regions may differ in terms of access to intermediaries as well as in the distribution of income within a region. Both of these factors would influence the return to
} 
The key finding here is that the insulation from the inflation tax through the $R$-rule disappears. That is, the inflation induced by fiscal policy in region 1 is passed onto region 2 agents. In contrast, a $\sigma-$ rule limits the spillover to the effect of region 1 fiscal policy on real wages.

Region 1 agents have the same budget constraints and hence the same first-order conditions as earlier. So, (6) continues to hold for region 1 agents. Inserting the government and intermediary constraints into the budget constraints of the private agents, we can determine equilibrium consumption levels. For region 1 which has an active fiscal authority, we again find

$$
c_{y}^{1}=w-\frac{k+\lambda b}{(1-\lambda) \eta^{1}} \quad c_{o}^{1}=\frac{k}{(1-\lambda) \eta^{1}} R-\frac{b}{\eta^{1}} \lambda \tilde{\pi}+T^{1} .
$$

For region 2 agents, their first order condition is

$$
u^{\prime}\left(w-s^{2}\right)=\tilde{\pi} v^{\prime}\left(s^{2} \tilde{\pi}+T^{2}(k, b)\right)
$$

Here $\tilde{\pi}=\frac{1}{\pi}$ is the inverse of the inflation rate. For region 2 agents, $s^{2}$ is just their real money demand. The consumption levels of region 2 agents are given in (38).

Fixed Money Growth Under a $\sigma$-rule, the money supply grows at a constant rate and this determines the transfer function $T(k, b)$. With $\lambda>0$, it is not possible to satisfy (37) with a fixed value of $k$ as $b$ varies. That is, $b$ matters for equilibrium allocations here, as in Proposition 4.

Looking at the consumption levels in (38), region 2 agents are insulated from the effects of region 1 fiscal policy on the return to their saving. That is, by fixing the money growth rate the $C B$ is fixing the inflation rate which is the return on saving of region 2 agents. As was the case under the $R$-rule before, the real wage is influenced by $b$. Further, unless $\phi^{2}=0$, region 2 agents will be directed affected by the transfers of the $C B$. Thus when region 2 agents hold only real money balances, the $\sigma-r u l e$ rule partially insulates them from region 1 fiscal policy.

Pegging the Return on Deposits If the $C B$ pegs the interest rate on deposits, agents in region 2 will pay the inflation tax. The interest rate is again given by $R=(1-\lambda) r(k)+\lambda \tilde{\pi}$. As before, if $b$ increases, $k$ must fall given $R$. This will increase $r$ and hence $\tilde{\pi}$ will be lower to keep $R$ fixed so $\pi$ will be higher.

The inflation has a welfare effect on region 2 agents since they hold money as a store of value. An increased deficit in region 1 induces an inflation tax on region 2. This effect comes on top of the effects of $b$ on the wage and the interest rate.

\subsection{Complete Segmentation within a Monetary Union}

We can also study an extreme case in which there are no physical capital flows, no flows of goods and no intermediary flows between the regions. Then the only link between agents in the different regions is a common currency.

holding money versus deposits. The regions with higher costs of intermediation and lower levels of income would have more money holders and thus would be more exposed to regional fiscal policy that induces inflation. 
With region specific capital stocks, the $C B$ transfer function would be written as $T\left(k_{1}, k_{2}, b\right)$. In this way the transfers to each of the regions would depend on the bonds issued by region 1 and the capital stocks of the two regions.

With this economic structure, the only effects of region 1 fiscal policy on region 2 agents would be through the effects of $b$ on $T(\cdot)$. The insulation of region 2 agents could arise from the adoption of a monetary policy which provided no transfers to region 2 agents: $\phi^{2}=0$. It could also arise if the transfer function for region 2 was by design independent of the capital stock in region 1. If, to the contrary, the $C B$ undertook a policy to stabilize interest rates in the federation, then fiscal spillovers could reemerge.

\section{Conclusion}

This paper studies the interplay between monetary policy rules and regional fiscal policies in a monetary union. In the presence of frictions, modeled here as a reserve requirement, the fiscal policy decisions of one region will generally affect relative prices, and thus spillover to other regions.

Propositions 5 and 6 indicate that there does not exist a $C B$ policy which insulates agents in the two regions from the fiscal policy of region 1. A key to these results is that any attempt to offset the fiscal policy of one region requires active intervention of the $C B$ through transfers. Even if the $C B$ succeeds in offsetting the effects of one region's fiscal policy on interest rates and/or wages, the required intervention will create income effects through transfers.

Under some conditions stipulated in Proposition 4, increased debt by region 1 leads to lower capital economy wide. These effects impact on the wages and interest rates of region 2 agents.

The exact nature of the spillover is influenced by monetary policy. This is brought out by our analysis of three leading policies: fixing the growth rate of the nominal money supply, pegging an interest rate or paying interest on reserves. Paradoxically, some rules that appear to be 'accommodating' and responsive to fiscal actions of regional governments, actually mitigate these spillovers. As we have seen, a monetary rule that pegs the interest rate may partially insulate one region from another. This insulation happens despite the fact that the monetary authority is using an inflation tax to peg a real interest rate.

We have briefly highlighted the fact that the insulating properties of monetary policy depend on asset market participation of agents. We leave to future research more general study of fiscal and monetary interactions when asset market participation is endogenous.

Our analysis has focused on steady states. As in Smith (1994), the choice of rules may also have interesting implications for local dynamics. 


\section{References}

Carlstrom, C., and T. Fuerst (1995): "Interest Rate Rules vs. Money Growth Rules: A Welfare Comparison in a cash-in-advance Economy," Journal of Monetary Economics, 36, 247-67.

Chatterjee, S., and D. Corbae (1992): "Endogenous Market Participation and the General Equilibrium Value of Money," Journal of Political Economy, 100(3), 615-46.

Diamond, P. (1965): "National Debt in a Neoclassical Growth Model," American Economic Review, 55(5), $1126-50$.

Freeman, S., And J. H. Haslag (1996): "On the optimality of interest-bearing reserves in economies of overlapping generations," Economic Theory, 7, 557-565.

Kehoe, P. (1987): "Coordination of Fiscal Policies in a World Economy," Journal of Monetary Economics, 19, 349-76.

Sмiтн, B. (1994): "Efficiency and Determinacy of Equilibrium under Inflation Targeting," Economic Theory, $4(3), 327-44$. 